\title{
Eficiência de óleos essenciais na qualidade sanitária e fisiológica em sementesde feijão-fava (Phaseolus lunatus L.)
}

GOMES, R.S.S.1*; NUNES, M.C.2; NASCIMENTO, L.C.1; SOUZA, J.O.'; PORCINO, M.M. ${ }^{2}$

1Universidade Federal da Paraíba, Programa de Pós-graduação em Agronomia, Rodovia Professor José Farias da Mata, PB 079, km 12, 59.397-000, Areia, PB, Brasil. 2Universidade Federal da Paraíba, Centro de Ciências Agrárias, Rodovia Professor José Farias da Mata, PB 079, km 12, 59.397-000, Areia, PB, Brasil. *Autor para correspondência: pratacca@gmail.com

RESUMO: A espécie Phaseolus lunatus L., conhecida popularmente como feijão-fava constitui uma das alternativas de renda e alimentação para a população da região Nordeste do Brasil. Um dos problemas enfrentados são as doenças que provocam grandes perdas na produção de sementes. O presente trabalho objetivou avaliar a eficiência dos óleos essenciais de copaíba, cravo-da-índia e manjericão na redução da incidência de fungos associados às sementes de feijão-fava, e sua interferência na qualidade fisiológica. Os tratamentos foram constituídos por óleos essenciais de copaíba, cravo-da-índia e manjericão nas concentrações de 0; 1; 1,5 e $2 \mathrm{~mL}$. L-1e fungicida (Captan ${ }^{\circledast}$ ). Foram utilizadas 200 sementes por tratamento. Para análise da qualidade sanitária das sementes foi adotado o método de incubação em placas de Petri contendo dupla camada de papel-filtro umedecida com ADE, sob temperatura de $20 \pm 2{ }^{\circ} \mathrm{C}$, por 7 dias. A qualidade fisiológica das sementes foi determinada com base nos testes de germinação, emergência e vigor das sementes. Para o teste germinação foi empregado método de rolo de papel germitest e na emergência osemeio foi realizado em bandejas plásticas contendo areia lavada esterilizada, em condição de casa de vegetação, e após 9 dias da instalação foi determinado o vigor com base nos resultados de índice de velocidade de germinação e emergência; comprimento da parte aérea, raiz primária e plântula; e teor de massa seca da partes aérea, raízes e plântulas de feijão-fava. O delineamento experimental foi interiamente casualizados, em esquama de fatorial simples $(3 \times 4)+1$ (óleos essenciais $x$ concentrações + fungicida), com quatro repetições de 50 sementes. Os óleos essenciais de copaíba e manjericão reduziram consideravelmente o percentual de incidência dos fungos associados as sementes de feijão-fava. O óleo essencial de cravo-da-índia na concetração de $2 \mathrm{~mL}$. L-1, reduziu a qualidade fisiológica das sementes de feijão-fava.

Palavras-chave:Copaifera langsdorffii, Caryophyllus aromaticus, Ocimum basilicum, Sanidade, Qualidade fisiológica.

\begin{abstract}
Efficiency of essential oils in the sanitary and physiological quality of lima bean seeds (Phaseolus lunatus L.). The Phaseolus lunatus L. species, popularly known as lima bean, is one of the alternative sources of income and food for the population of Northeast Brazil. One of the problems is the diseases that cause great losses in seed production. This study evaluated the effectiveness of essential oils of copaiba, clove, and basil in reducing the incidence of fungi associated with lima bean seeds, as well as the effect on their physiological quality. The treatments consisted of essential oils of copaiba, clove, and basil at concentrations of $0 ; 1 ; 1.5$; and $2 \mathrm{~mL}$. L-1 and fungicide (Captan $\left.{ }^{\circledR}\right)$. A total of 200 seeds were used per treatment. To analyze the sanitary quality of the seeds, the method used was incubation in petri dishes containing a double layer of filter paper moistened with distilled sterilized water at a temperature of $20 \pm 2^{\circ} \mathrm{C}$, for seven days. The physiological quality of the seeds was determined by testing their germination, emergence, and vigor. For the germination test, the method used was a roll of Germitest paper. For the emergence, the seeds were sown in plastic trays containing washed sterilized sand in greenhouse conditions. After nine days, the vigor was determined based on the results of germination and emergence speed rates; length of the aerial part, primary root, and seedling; and dry matter content of the aerial part, roots, and seedlings of the lima beans.
\end{abstract}

Recebido para publicação em 23/06/2015

Aceito para publicação em 19/01/2016

10.1590/1983-084X/15_117

Rev. Bras. PI. Med., Campinas, v.18, n.1, supl. I, p.279-287, 2016. 
The experimental design was completely randomized in a simple factorial arrangement $(3 \times 4)+1$ (essential oils $x$ concentrations + fungicide) with four replications of 50 seeds. The essential oils of copaiba and basil considerably reduced the percentage of incidence of the fungi associated with lima bean seeds. The essential clove oil at $2 \mathrm{~mL}$. L-1 reduced the physiological quality of the lima bean seeds.

Keywords: Copaifera langsdorffii, Caryophyllus aromaticus, Ocimum basilicum, sanitation, physiological quality.

\section{INTRODUÇÃO}

O feijão-fava (Phaseolus lunatus L.) pertence à família Fabaceae, originária da Guatemala, é a segunda leguminosa de maior importância do gênero Phaseolus, por apresentar alto valor nutritivo, contendo vitaminas, proteínas e sais minerais, que são elementos essenciais na nutrição humana e vem sendo uma das alternativas de renda e alimento para a população da região Nordeste (Penha, 2014).

A Paraíba tem essa cultura como de alta relevância econômica uma vez que a sua produtividade equivale a $42 \%$ em relação a região Nordeste, sendo uma espécie cultivada em quase todas as microrregiões do Estado, destacando-se os municípios de Queimadas, Aroeiras, Campina Grande, Alagoa Nova, Alagoa Grande e Natuba, obtendo uma produção de aproximadamente 2.830 t de grãos de fava, numa área plantada de 12.130 ha, na safra de 2013 (IBGE, 2015).

A qualidade sanitária das sementes é um dos mais importantes aspectos relacionados à produtividade, devido ao grande número de patógenos que podem estar associados a elas. Microrganismos podem causar anormalidades e lesões nas plântulas, bem como deterioração do tecido embrionário, comprometendo a germinação e vigor das sementes e consequentemente perdas de produção (Moreau, 2011; Piveta et al., 2010).

Aqualidade fisiológica da semente é importante para a avaliação de um lote, pois influencia diretamente no desempenho, taxa de emergência, emergência total das plântulas, viabilidade e manutenção do alto vigor, favorecendo uma maior velocidade nos processos metabólicos, propiciando emissão mais rápida e uniformidade da raiz primária no processo de germinação, alta taxa de crescimento, produzindo plântulas com maior tamanho inicial e alta produtividade (Munizzi et al., 2010).

A agricultura moderna tem buscado alternativas ecológicas como a utilização de óleos essenciais no controle de patógenos presentes nas sementes, pois, além de reduzir o uso de produtos químicos, diminui os riscos à saúde humana e preserva o meio ambiente. Além disso, conservar os aspectos fisiológicos e sanitários das sementes, viabiliza a produção, agregando valores ao produto final, atendendo às exigências do mercado e fortalecendo a economia na agricultura familiar (Barrocas \& Machado, 2010).

Os óleos essenciais são misturas complexas de substâncias voláteis, lipofílicas, com baixo peso molecular, geralmente odoríferas e líquidas. São constituídos na maioria das vezes, por moléculas de natureza terpênica, complexa de diversas classes de substâncias, dentre elas os fenilpropanóides, mono e sesquiterpenos, pertencentes ao metabolismo secundário das plantas (Morais, 2009). Nos vegetais, esses óleos puros apresentam toxicidade elevada, sendo recomendada a utilização em pequenas dosagens onde desenvolvem funções que estão relacionadas à sua volatilidade, agindo na proteção contra predadores e patógenos. Nesse contexto, recebem atenção especial, pelas atuação como fungicidas, herbicidas, inseticidas e nematicidas (Sodaeizadeh et al., 2010).

Estudos envolvendo a qualidade fisiológica e sanitária em sementes de milho (Zea mays L.), feijão-caupi (Vigna unguiculata (L.) Walp.) e barriguda (Pseudobombax marginatum A.St.-Hil.),submetidas ao tratamento com extrato etanólicode cravo-daíndia(Caryophyllus aromaticus L.), manjericão (Ocimum basilicum L.) e óleo essencial de copaíba (Copaifera langsdorffii Desf.),foram realizados por Mazzafera (2003) e Mondego et al. (2014), verificando-se que os tratamentos influenciaram diferentemente nos parâmetros analisados, de qualidade fisiológica e sanitária de sementes.

O presente trabalho objetivou avaliar a eficiência dos óleos essenciais de copaíba,cravoda-índia emanjericão na redução da incidência de fungos associados às sementes de feijão-fava, e sua interferência na qualidade fisiológica.

\section{MATERIAL E MÉTODOS}

O presente trabalho foi desenvolvido nos Laboratórios de Fitopatologia e Biotecnologia de Sementes, pertencentes ao Departamento de Fitotecnia e Ciências Ambientais, da Universidade Federal da Paraíba.

As sementes de feijão-fava (Phaseolus lunatus L.) do genótipo Lavandeira, também

Rev. Bras. PI. Med., Campinas, v.18, n.1, supl. I, p.279-287, 2016. 
conhecida por Orelha-de-vó foram coletadas em campo de produção na zona rural de Galante (07018'13" S de latitude e 3546'14" W de longitude), distrito de Campina Grande, Estado da Paraíba.

Os tratamentos foram constituídos por óleos essenciais de copaíba (Copaifera langsdorffii Desf.), cravo-da-índia (Caryophyllus aromaticus L.) e manjericão (Ocimum basilicum L.) nas concentrações de $0 ; 1 ; 1,5$ e $2 \mathrm{~mL}$. L-1 de ADE, acrescidos de Tween 80 a 0,05\% (v/v) para facilitar a emulsificação dos óleos em água (Brito et al., 2010) e o fungicida Captan ${ }^{\circledast}\left(240\right.$ g. i.a. $100 \mathrm{~kg}^{-1} \mathrm{de}$ sementes). A testemunha 0 (zero) correspondeu apenas à imersão das sementes em água destilada e esterilizada (ADE).

As sementes foram imersas nos tratamentos, conforme descritos anteriormente, durante $3 \mathrm{~min}$ e o fungicida foi aplicado diretamente sobre as sementes. Após a aplicação dos tratamentos, as sementes foram distribuídas sobre o papel filtro contindos nas placas, e mantidas por um período de 7 dias em temperatura de $20 \pm 2{ }^{\circ} \mathrm{C}$, sob fotoperíodo de 12 h (Brasil, 2009).

Para a detecção de fungos presentes nas sementes, adotou-se o método de incubação em placas de Petri, com $15 \mathrm{~cm}$ de diâmetro, contendo dupla camada de papel de filtro umedecida com ADE. Foram utilizadas 200 sementes por tratamento, anteriormente desinfestadas em álcool $70 \%$ por 30 segundos e hipoclorito de sódio à $1 \%$, por 2 minutos, permanecendo-as sob temperatura de $25 \pm 2{ }^{\circ} \mathrm{C}$, para secagem.

A identificação dos fungos associados às sementes foi realizada através de microscópico estereoscópico (Menezes \& Assis, 2004) em comparação com literatura especializada. Os resultados de incidência de fungo foram expressos em percentual de sementes infectadas.

Para a avaliação da germinação e índice de velocidade da geminação das sementes,foi adotado o método papel tipo germitest umedecido com ADE com o equivalente a 2,5 vezes o peso da massa do papel e colocadas para germinar em câmara de B.O.D (Biochemical Oxygen Demand) em temperatura de $25^{\circ} \mathrm{C}$, sob fotoperíodo de $12 \mathrm{~h}$ (Brasil, 2009).

As avaliações foram realizadas diariamente, até o nono dia após a instalação, obtendo-se os valores de porcentagem média de sementes germinadas, em que foram consideradas sementes germinadas aquelas que apresentaram sistema radicular com pelo menos $2 \mathrm{~mm}$ de comprimento (Brasil, 2009). O IVG foi avaliado pelo número de sementes germinadas diariamente de acordo com a fórmula proposta por Maguire (1962), onde IVG $=\Sigma\left(G_{1} / N_{1}+G_{2} / N_{2}+G_{n} / N_{n}\right)$, em que IVG = índice velocidade de germinação; $G_{1}, G_{2}$ e $G_{n}=$ número de plântulas germinadas a cada dia; $\mathrm{N}_{1}, \mathrm{~N}_{2}$ e $\mathrm{N}_{\mathrm{n}}$ = número de dias após a instalação na primeira, segunda e última contagem.

Para observação da emergência e o índice de velocidade da emergência em plântulas, utilizou-se o mesmo número de sementes por repetição, sendo semeadas em bandejas plásticas com diâmetro de $47 \times 27 \times 8 \mathrm{~cm}$ na profundidade de $1 \mathrm{~cm}$, contendo areia lavada esterilizada, e umedecidas diariamente com quantidade de água equivalente a $60 \%$ da sua capacidade de retenção, ficando as bandejas distribuídas ao acaso dentro da casa de vegetação, sob temperatura entre 25 a $30^{\circ} \mathrm{C}$, por 9 dias (Alves et al. 2014). Os resultados foram expressos em percentual de plântulas normais emergidas no quinto e nono dia após a instalação, obtendo-se os valores de porcentagem na primeira contagem e emergência de plântulas, repectivamente. O índice de velocidade de emergência foi representado pelo número de plântulas emergidas diariamente até o nono dia após a instalação,conforme a fórmula adaptada de Maguire (1962).

O vigor das sementes foi avaliado com base nos parâmetros do índice de velocidade da germinação e emergência, comprimento da parte aérea e raiz primária e o teor de massa seca da parte aérea e raiz primária. Utilizaram-se 10 plântulas por repetição, provenientes do teste de emergência, para determinar comprimento de parte aérea, raiz primaria e plântula com o auxílio de régua milimétrica, e ao final da avaliação os resultados foram expressos em $\mathrm{cm}$. plântula ${ }^{-1}$. Já o teor de massa seca da partes aéreas, raízes e plântulas, foi obtido por meio do corte transversal do colo da plântula, com o auxílio de um bisturi, e levados à estufa termoelétrica de circulação forçada de ar a $70 \pm 2^{\circ} \mathrm{C}$, por $48 \mathrm{~h}$ para secagem. Após esse período, as amostras foram colocadas para esfriar em dessecador, tendo o peso da sua massa seca determinada em balança de precisão $0,001 \mathrm{~g}$, e os resultados expressos em gramas (Larré et al., 2014).

O delineamento experimental foi inteiramente casualizado em esquema fatorial simples 3x4+1 (óleos essenciais $x$ concentrações + fungicida), tendo o modelo de regressão ajustado, e as médias comparadas pelo teste de Scott$\operatorname{Knott}(p<0.05)$ no programa estatístico ASSISTAT ${ }^{\circledR}$ versão beta 7.7 (Silva, 2014). Para cada tratamento foram utilizadas 200 sementes, divididas em quatro repetições de 50 sementes.

\section{RESULTADOS E DISCUSSÃO}

O maior percentual de incidência de fungos associados as sementes de feijão-fava, foram representados por Aspergillus spp. (4,2\%) e

Rev. Bras. PI. Med., Campinas, v.18, n.1, supl. I, p.279-287, 2016. 
Fusarium sp. (3,1\%), e de menor expressão pelos fungos Rhizopus sp. (1,85\%), Aspergillus niger $(1,69 \%)$, Monilia sp. $(1,67 \%)$, Cladosporium sp. $(1,13 \%)$ e Botrytis sp. $(0,27 \%)$, Colletotrichum sp. $(0,03 \%)$, Penicillium sp. $(0,73 \%)$ e Periconia sp. $(0,02 \%)$ (Figura 1).

Foi observado efeito significativo $(p<0,05)$ entre as concentrações dos óleos essenciais de copaíba, cravo-da-índia e manjericão (Figura 2), e as médias foram ajustadas ao modelo quadrático de regressão para os tratamento com copaíba e manjericão e linear para as concentrações de cravo-da-índia.

Mendonça et al. (2009) testando isolamento e identificação de fungos com potencial patogênico para a saúde humana em material vegetal de uso medicinal comercializado em Manaus, observaram que Aspergillus sp., é fungo associado à deterioração de sementes de feijão-fava em condições de armazenamento inadequado, mais a contaminação também pode ocorrer logo após a colheita. Esse, gênero pode causar grandes prejuízos econômicos aos produtores.

Foi observada redução no percentual de incidência do Aspergillus spp. nas sementes tratadas com o óleo de manjericão na concentração de $1 \mathrm{~mL}$. $\mathrm{L}^{-1}$, não diferindo estatisticamente do tratamento com fungicida (Figura 2). A máxima redução de Aspergillus spp. foi estimada nas concentrações de 1,24 e $1,22 \mathrm{~mL}$. $\mathrm{L}^{-1}$, respectivamente, e linear

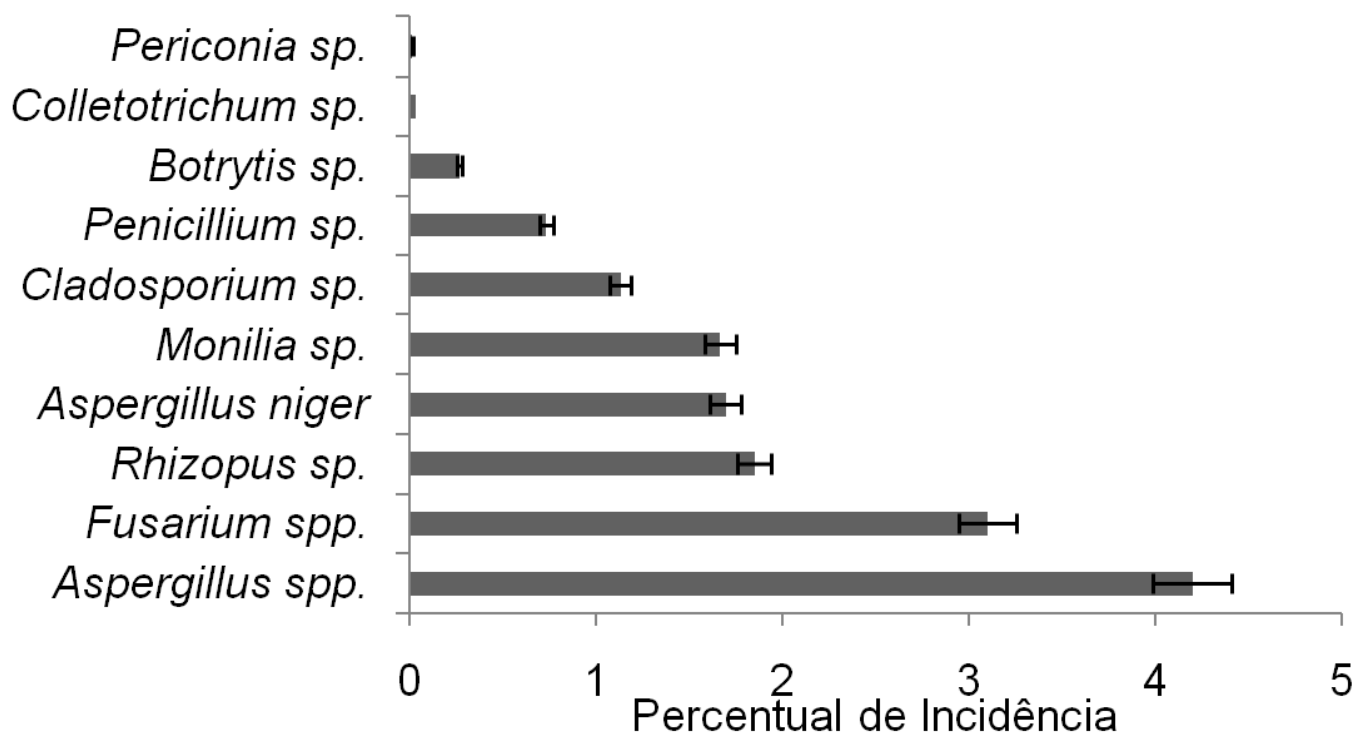

FIGURA 1. Valores médios de percentual de incidência de fungos em sementes feijão-fava 'Lavandeira'.

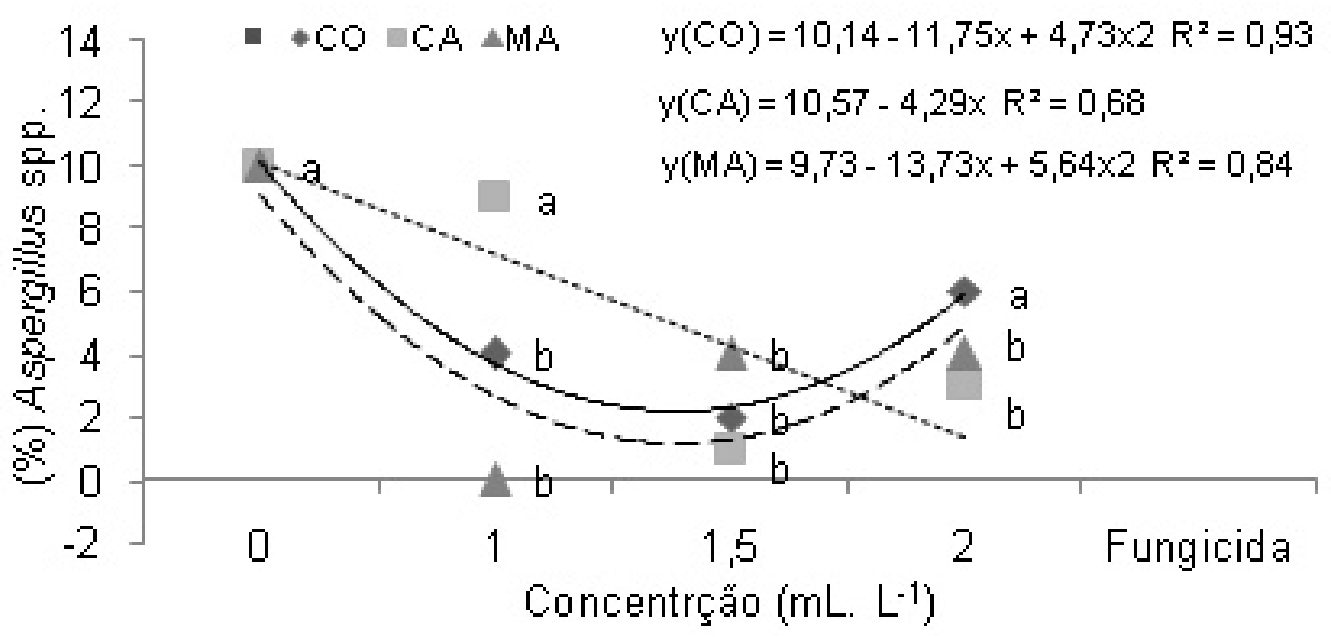

FIGURA 2. Percentual de incidência de Aspergillus spp. em sementes de feião-fava 'Lavandeira', submetidas a diferentes concentrações dos óleos essenciais de copaíba (CO), cravo-da-Índia (CA) e manjericão (MA). 


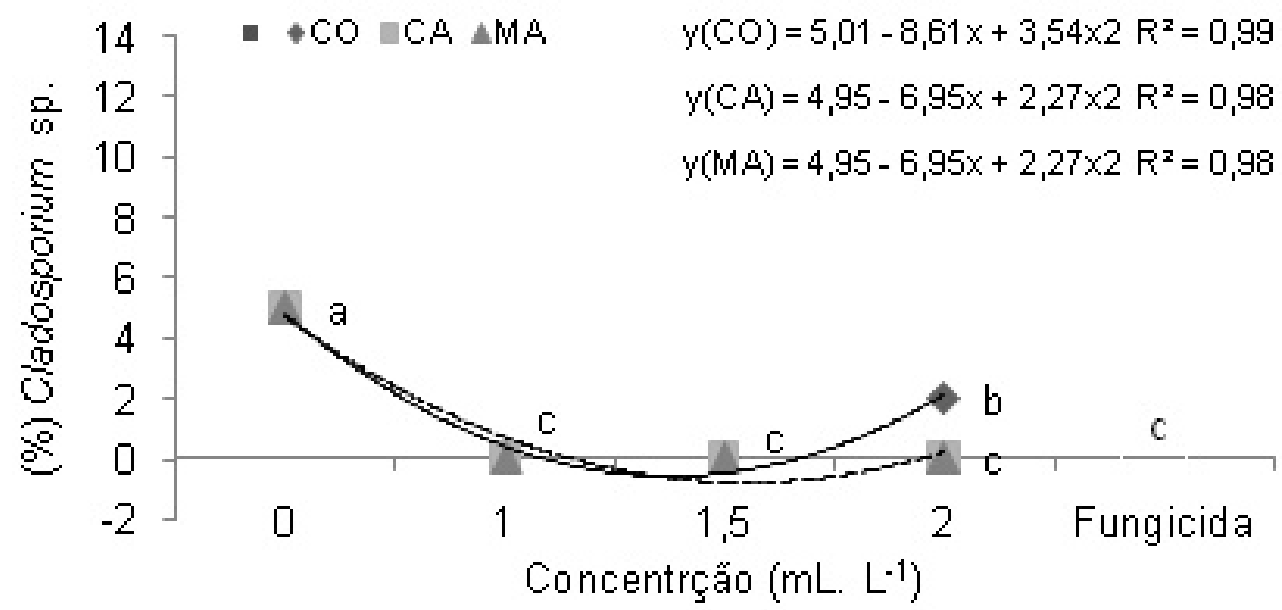

FIGURA 3. Percentual de incidência de Cladosporium sp. em sementes de feião-fava 'Lavandeira', submetidas a diferentes concentrações dos óleos essenciais de copaíba (CO), cravo-da-Índia (CA) e manjericão (MA).

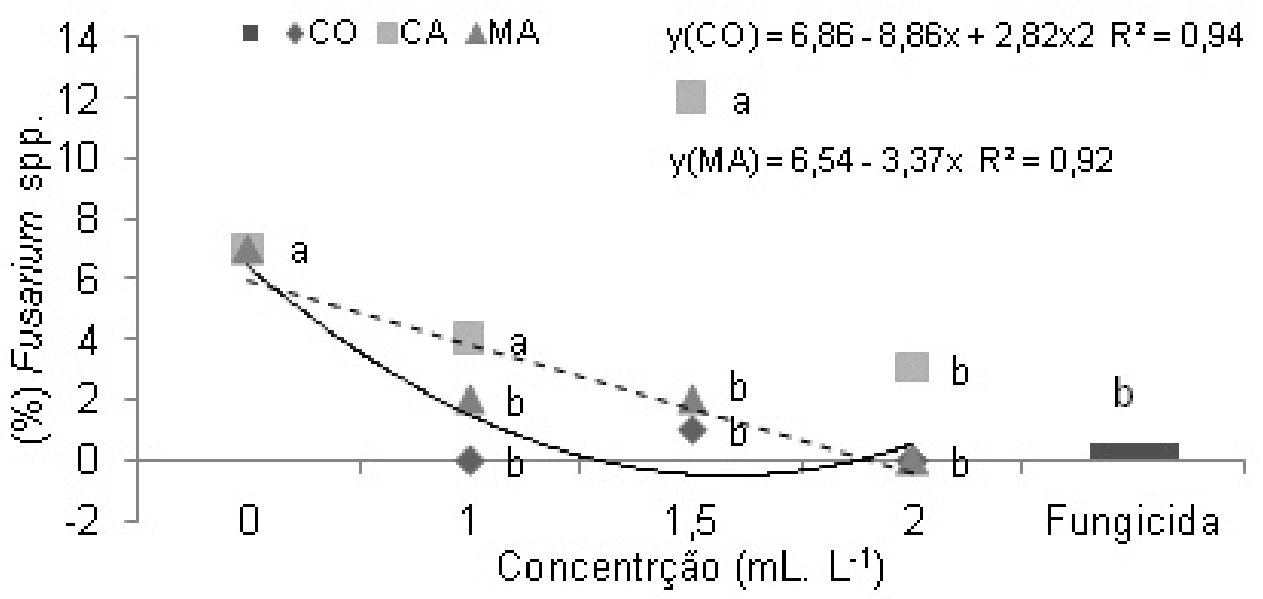

FIGURA 4. Percentual de incidência de Fusarium spp. em sementes de feião-fava 'Lavandeira', submetidas a diferentes concentrações dos óleos essenciais de copaíba (CO), cravo-da-Índia (CA) e manjericão (MA).

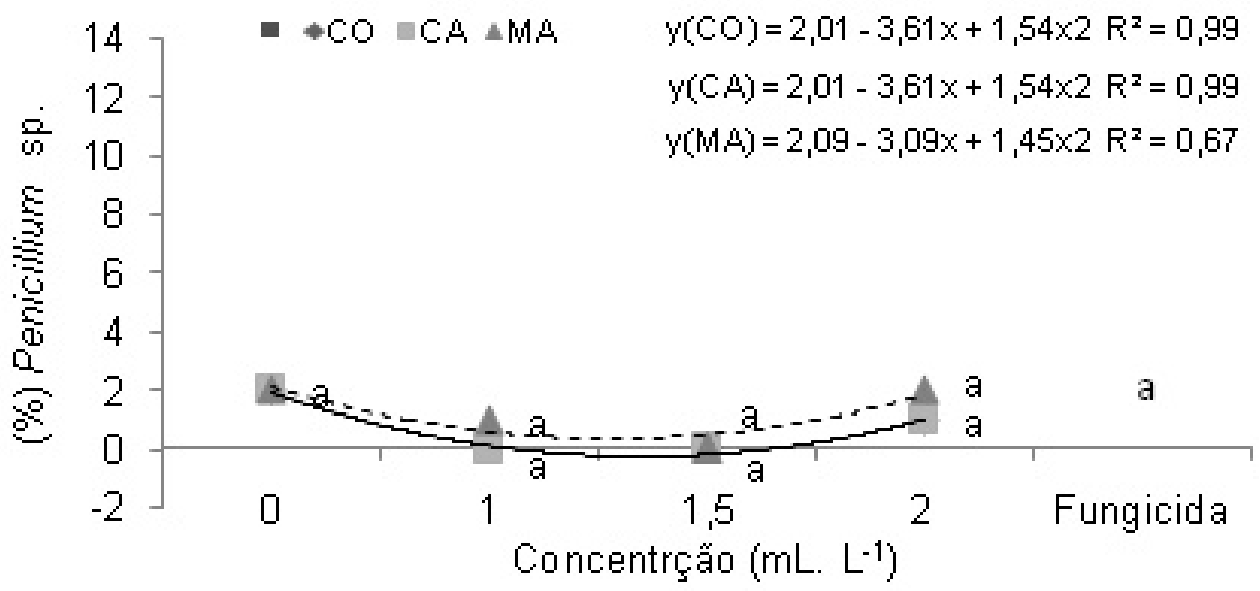

FIGURA 5. Percentual de Incidência de Penicillium sp. em sementes de feião-fava 'Lavandeira', submetidas a diferentes concentrações dos óleos essenciais de copaíba (CO), cravo-da-Índia (CA) e manjericão (MA).

Rev. Bras. PI. Med., Campinas, v.18, n.1, supl. I, p.279-287, 2016. 
para o tratamento a base de óleo de cravo-daíndia que apresentou efeito positivo na redução do fitopatógeno na concentração máxima utilizada (Figura 2).

Segundo Zimmermam-Franco et al. (2013) estudando atividade antifúngica do óleo essencial de $C$. langsdorffii verificou-se que as principais substâncias encontradas foram os $\beta$-cariofileno e os compostos ácidos caurenóico e $\gamma$-muurolene, notificados por possuírem propriedades antibacterianas e antifúngicas.

Mondego et al. (2014) pesquisando métodos de controle alternativo da microflora em sementes de Pseudobombax marginatum com óleo essêncial de copaíba, para a incidência de Curvularia sp., observaram que todas as doses do óleo diferiram significativamente da testemunha $(7 \%)$ e não diferiram do fungicida (Captan ${ }^{\circledR}$ ).

Os tratamentos a base óleos de copaíba, cravo-da-índia e manjericão, apresentaram efeito significativo $(p<0,05)$ entre as concentrações,e foi verificada uma máxima redução no percentual de incidência do Cladosporium sp., a partir da concentração de $1,53 \mathrm{~mL}$. L-1 para os óleos essenciais de cravo-da-índia e manjericão, através da derivação da equação, e de $1,21 \mathrm{~mL}$. $\mathrm{L}^{-1}$ para o óleo de cobaíba (Figura 3).

Ibrahim et al. (2012), constataram que óleos essenciais de cravo-da-índia e manjericão apresentaram concentrações de eugenol e carvacrol, e quando acrescentados meio de cultura foram observadas de formações significativas na morfologia e no crescimento celular em hifas de Cladosporium herbarumem relação à sua idade, esses fenômenos foram acompanhados por alterações macroscópicas da colônia em combinação com a inibição substancial de crescimento.

Ocorreu efeito significativo $(p<0,05)$ nas concentrações dos óleos essenciais de copaíba, cravo-da-índia e manjericão com redução e controle de Fusarium spp. (Figura 4).

As médias foram ajustadas ao modelo quadrático e linear de regressão para os tratamentos a base de copaíba e manjericão (Figura 4). Para o extrato de cravo-da-india não houve ajuste do modelo de regressão para a equação.

Foi verificado que a partir da concentração de $1,57 \mathrm{~mL}$. L-1 do óleo de copaíba, mostrou-se eficiente ao reduzir a incidência de Fusarium spp. e o óleo de manjericão apresentou efeito na máxima redução do fungo quando utilizado sua máxima concentração (Figura 4).

Santos et al. (2010) estudando efeito dos óleos essenciais de aroeira-periquita (Schinus molle L). e aroeira-vermelha (Schinus terebinthifolius Raddi), verificaram que os mesmos apresentam efeito fungicida contra Alternaria spp., Fusarium spp., Collethotricum spp. e Botrytis spp. e o óleo essencial de aroeira-vermelha apresenta efeito fungicida mais pronunciado contra Botrytis spp. Além disso,constataram altos teores de eugenol nos óleos essenciais de aroeira-periquita e aroeira-vermelha, o que evidência comportamento semelhante em relação a inibição do Fusarium spp., por estar ligado diretamente a composição de compostos secundaria presentes nos óleos essenciais estudados .

Com base na análise de regressão (Figura 5 ), pode-se observar o efeito sinérgico entreas concentrações dos óleos essenciais de cobaíba, cravo-da-índia e manjericão, sobre a redução do percentual de incidência do Penicillium sp., com a derivação da equação as concentrações estimadas

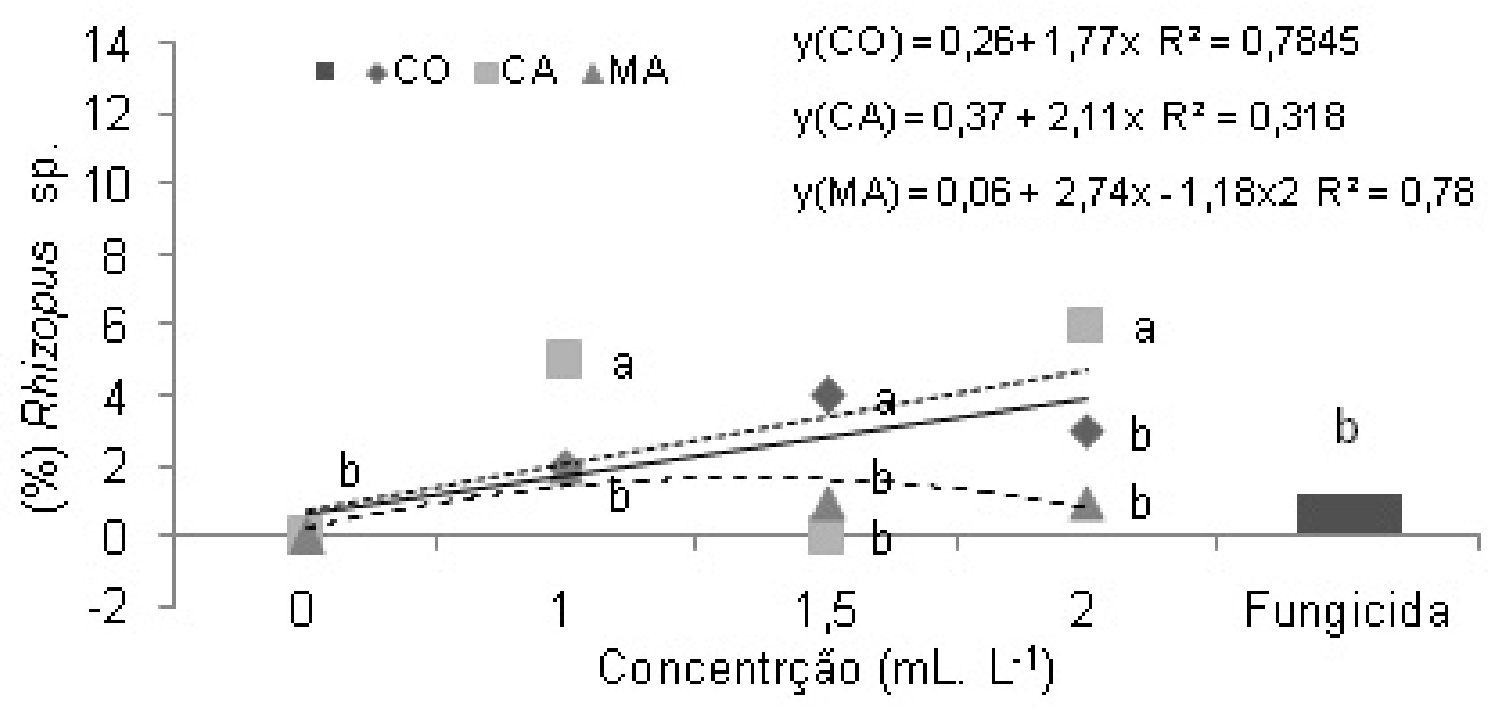

FIGURA 6. Percentual de incidência de Rhizopus sp. em sementes de feião-fava 'Lavandeira', submetidas a diferentes concentrações dos óleos essenciais de copaíba (CO), cravo-da-Índia (CA) e manjericão (MA).

Rev. Bras. PI. Med., Campinas, v.18, n.1, supl. I, p.279-287, 2016. 
de 1,17 mL. L-1 dos óleos de copaíba e cravo-da-índia e de $1,07 \mathrm{~mL}$. L-1 do manjericão, proporcionaram inibição máxima do Penicillium sp.(Figura 5), superando o tratamentos com fungicida.

Mendonça et al. (2009), avaliando o efeito de Penicillium sp. sobre sementes de paricá (Schizolobium amazonicum Herb.), verificaram que esse fungo está associado à deterioração de sementes em condições de armazenamento inadequado, podendo haver contaminação logo após a colheita. Entretanto, verificou-se que além disso patógeno apresentar potencial para favorecer o surgimento de novas doenças.

Combrinck et al. (2011) estudando atividade in vitro de dezoito óleos essenciais e alguns componentes principais contra patógenos, tais como: Alternaria spp.; Botrytis cinerea; Colletotrichum gloeosporioides; Lasiodiplodia theobromae e Penicillium spp.,observaram efeito fungistático e fungicida apresentados pelos óleos essenciais que podem estar relacionados com a presença de componentes majoritários, como o eugenol, podendo ter ocorrido efeito sinérgico entre os componentes do óleo essencial, levando a efetividade no controle antifúngico sobre o crescimento, germinação e esporulação de Penicillium sp.

Houve diferença significativo $(p<0,05)$ entre as concentrações dos óleos essenciais aplicados as sementes para controlar o Rhizopus sp. (Figura 6). Entretando, o óleo de manjericão mostrou-se eficiente na redução da incidência do Rhizopus sp. a partir da concentração de 1,16 mL. L-1 (Figura 6).

Silva \& Pasin (2006) estudando efeito de extrato aquoso capim-limão (Cymbopogon citratus (DC) Staupf.), manjericão e piracá (Vernonia scorpioides (Lam.) Pers). No tratamentos de sementes de girassol (Helianthus annuus L.) verificaram redução na incidência Rhizopus sp. nas sementes tratadas com extrato de manjericão.

Os resultados obtidos na avaliação do teste de germinação nas sementes, não apresentaram diferenças significativas entre os tratamentos quando avaliadas primeira contagem da germinação, germinação e índice de velocidade da germinação, obtendo-se os valores médios variando de 84 a $92 \%$ para primeira contagem, 88 a $92 \%$ de sementes germinadas e para o índice de velocidade da germinação ficou entre 9,4 a 10,0.

Ocorreu diferença significativa na interação entre óleos essenciais versus concentrações, quando avaliada a porcentagem de plântulas normais emergidas na primeira contagem, emergência e no índice de velocidade da emergência (Tabela 1).

Foi evidenciado efeito negativo para as variáveis primeira contagem e índice de velocidade da emergência em função da aplicação da concentração de $2 \mathrm{~mL}$. $\mathrm{L}^{-1}$ dos óleos essenciais de cravo-da-índia e manjericão, houve também redução significativa no percentual de emergência de plântulas tratadas com $2 \mathrm{~mL}$. $\mathrm{L}^{-1}$ do óleo de manjericão (Tabela 1).

Oliveira et al. (2011) afirmaram que óleos essenciais com presença de eugenol, que é um fenil propeno (fenol) pouco solúvel em água, presente no óleo essencial de certas plantas como manjericão e cravo-da-índia é um composto que em alta concentração pode ser tóxico e se liga fortemente ao tanino por meio de pontes de hidrogênio inibindo a germinação. Souza Filho et al. (2009) presumiram que o eugenol estão em maior concentração nos óleos essenciais, e extratos brutos superiores a $25 \%$, causando toxicidade nas sementes.

Comportamento semelhante foi verificado por Viegas et al. (2005) estudando sementes de amendoim (Arachis hypogaea L.), tratadas com óleo de alho (Allium sativum L.) e canela (Cinnamomun zeilanicum Breyn.), em que houve redução acentuada da germinação e aumento considerável da porcentagem de plântulas anormais deterioradas, principalmente, por fungos dos gêneros Aspergillus sp., Penicillium sp. e Rhizopus sp.

Nas análises de comprimento da parte aérea, raiz primária e plântula, houve diferença significativa na interação óleos essenciais versos concentrações, conforme dados apresentados na Tabela 2.

Quando utilizados os tratamentos com óleo de cravo-da-índia na concentração de $2 \mathrm{~mL}$. $\mathrm{L}^{-1}$ e o manjericão na concentração de $1 \mathrm{~mL}$. L-1, foi observada redução no comprimento da parte aérea e plântula, influenciando negativamente no vigor das plântulas e diferindo estatisticamente dos demais tratamentos (Tabela 2).

Brito et al.(2010)estudando os efeitos de óleos essenciais de canela e manjericão na germinação de sementes de mandacaru (Cereus jamacaru P. DC.), observaram redução na germinação das sementes tratamento com óleo de manjericão, apresentando menor valor de massa seca e tamanho das plântulas, interferindo negativamente no vigor das sementes de mandacaru.

Os compostos timol, metil-chavicol, linalol, eugenol, cineol e pireno em maior concentração, presentes no óleo essencial de cravo-da-índia, influenciam na redução do comprimento da raiz primária e plântula Oliveira et al. (2011). Tal efeito foi observado no presente trabalho, nas concentrações a partir de 1,5 mL. L-1, (Tabela 2).

$\mathrm{Na}$ concentração de $1 \mathrm{~mL} \cdot \mathrm{L}^{-1}$ dos óleos de copaíba e cravo-da-índia, foram observados os maiores valores de comprimento de plântula $(31,0 \mathrm{~cm})$, e de $14,9 \mathrm{~cm}$ de comprimento paras as plântulas que receberam $1 \mathrm{~mL}$. $\mathrm{L}^{-1}$ do óleo de manjericão, ficando abaixo e massa seca dos

Rev. Bras. PI. Med., Campinas, v.18, n.1, supl. I, p.279-287, 2016. 
TABELA 1. Porcentagem de plântulas de feijão-fava 'Lavandeira' emergidas na primeira contagem, emergência e índice de velocidade da emergência (IVE), antes tratadas com diferentes concentrações dos óleos essenciais de copaíba (CO), cravo-da-Índia (CA) e manjericão (MA).

\begin{tabular}{|c|c|c|c|c|c|c|c|c|c|}
\hline \multirow{2}{*}{ Concentração } & \multicolumn{3}{|c|}{ Primeira contagem } & \multicolumn{3}{|c|}{ Emergência } & \multicolumn{3}{|l|}{ IVE } \\
\hline & $\mathrm{CO}$ & CA & MA & $\mathrm{CO}$ & CA & MA & $\mathrm{CO}$ & CA & MA \\
\hline OmL.L-1 & $15 a A^{*}$ & $15 \mathrm{aA}$ & $15 \mathrm{aA}$ & $20 a A$ & $20 a A$ & $20 \mathrm{aA}$ & $15,3 a A$ & $15,3 a A$ & $15,3 a A$ \\
\hline $1 \mathrm{~mL} \cdot \mathrm{L}^{-1}$ & $12 \mathrm{bB}$ & $21 \mathrm{aA}$ & $8 b C$ & $17 \mathrm{bB}$ & $29 a A$ & $13 a B$ & $13,2 \mathrm{bB}$ & $24,2 \mathrm{aA}$ & $9,5 b \mathrm{C}$ \\
\hline 1,5 mL.L-1 & $17 a A$ & $15 \mathrm{aA}$ & $12 \mathrm{aB}$ & $28 \mathrm{aA}$ & $18 \mathrm{aA}$ & $17 \mathrm{bA}$ & $22,1 \mathrm{aA}$ & $14,8 \mathrm{aA}$ & $12,8 \mathrm{bB}$ \\
\hline $2 m L . L^{-1}$ & $15 a A$ & $8 b B$ & $3 b c$ & $24 \mathrm{aA}$ & $19 a A$ & $8 \mathrm{bB}$ & $17,2 \mathrm{aA}$ & $11,8 \mathrm{bC}$ & $4,8 \mathrm{cD}$ \\
\hline Fungicida & $20 \mathrm{aA}$ & $20 \mathrm{aA}$ & $20 \mathrm{aA}$ & $25 \mathrm{Aa}$ & $25 a A$ & $25 a A$ & $21,5 \mathrm{aA}$ & $21,5 \mathrm{aA}$ & $21,5 \mathrm{aA}$ \\
\hline $\mathrm{cv} \%$ & & 9,57 & & & 9,39 & & & 9,51 & \\
\hline
\end{tabular}

'Médias seguidas de mesma letra minúscula na coluna e maiúsculas nas linhas, não diferem estatisticamente entre si para o teste de ScottKnott ao nível de $1 \%$ de probabilidade $(p<0,01)$.

TABELA 2. Comprimento $(\mathrm{cm})$ de parte aérea, raiz primaria e plântula de feijão-fava 'Lavandeira', tratadas com diferentes concentrações dos óleos essenciais de copaíba (CO), cravo-da-Índia (CA) e manjericão (MA).

\begin{tabular}{|c|c|c|c|c|c|c|c|c|c|}
\hline \multirow{2}{*}{ Concentração } & \multicolumn{3}{|c|}{ Parte aérea } & \multicolumn{3}{|c|}{ Raiz primaria } & \multicolumn{3}{|c|}{ Plântula } \\
\hline & $\mathrm{CO}$ & CA & MA & $\mathrm{Co}$ & CA & MA & $\mathrm{CO}$ & CA & MA \\
\hline $0 \mathrm{~mL} . \mathrm{L}^{-1}$ & $11,3 \mathrm{bA}$ & $11,3 \mathrm{bA}$ & $11,3 \mathrm{bA}$ & $9,5 \mathrm{bA}$ & $9,5 \mathrm{bA}$ & $9,5 \mathrm{bA}$ & $20,8 \mathrm{bA}$ & $20,8 \mathrm{bA}$ & $20,8 b A$ \\
\hline $1 \mathrm{~mL} \cdot \mathrm{L}^{-1}$ & $18,0 a A$ & $17,2 \mathrm{aA}$ & $9,0 \mathrm{bB}$ & $13,5 \mathrm{aA}$ & $14,3 a A$ & $5,9 \mathrm{cD}$ & $31,5 a A$ & $31,5 a A$ & $14,9 \mathrm{cC}$ \\
\hline $1,5 \mathrm{~mL} \cdot \mathrm{L}^{-1}$ & $17,3 a A$ & $14,2 \mathrm{aB}$ & $14,6 a B$ & $9,5 b A$ & $9,6 \mathrm{bA}$ & $9,8 \mathrm{bA}$ & $26,8 \mathrm{aA}$ & $23,9 b B$ & $24,4 \mathrm{bB}$ \\
\hline $2 \mathrm{~mL} \cdot \mathrm{L}^{-1}$ & $18,2 \mathrm{aA}$ & $11,5 b B$ & $17,3 a A$ & $11,1 \mathrm{aA}$ & $7,7 \mathrm{bB}$ & $16,7 a A$ & $29,3 a A$ & $19,2 \mathrm{bB}$ & $34,0 \mathrm{aA}$ \\
\hline Fungicida & $16,4 \mathrm{aA}$ & $16,4 \mathrm{aA}$ & $16,4 \mathrm{aA}$ & $12,4 \mathrm{aA}$ & $12,4 \mathrm{aA}$ & $12,4 \mathrm{aA}$ & $28,8 \mathrm{aA}$ & $28,8 \mathrm{aA}$ & $28,8 \mathrm{aA}$ \\
\hline $\mathrm{cv} \%$ & & 5,01 & & & 7,48 & & & 5,29 & \\
\hline
\end{tabular}

'Médias seguidas de mesma letra minúscula na coluna e maiúsculas nas linhas, não diferem estatisticamente entre si para o teste de ScottKnott ao nível de $1 \%$ de probabilidade $(p<0,01)$.

demais tratamentos (Tabela 2).

Para os resultados encontrados para massa seca da partes aérea, raíz e plântula,não foi observada diferença significativa entre os tratamentos, obtendo-se as médias de 0,4 a 0,9 g para massa seca de partes aérea; 0,3 a $0,4 \mathrm{~g}$ de massa seca de raízes e 0,7 a 1,43g de massa seca de plântulas.

\section{CONCLUSÃO}

Os óleos essenciais de copaíba e manjericão reduziram consideravelmente o percentual de incidência dos fungos associados as sementes de feijão-fava;

O óleo essencial de cravo-da-índia na concetração de $2 \mathrm{~mL}$. $\mathrm{L}^{-1}$, reduziu a qualidade fisiológica das sementes de feijão-fava.

\section{REFERÊNCIAS}

ALVES, A.U. et al. Emergência de plântulas de fava em função de posições e profundidades de semeadura.
Bioscience Journal, v.30, n.1, 2014.

BARROCAS, E.N.; MACHADO. J.C. Inovações tecnológicas em patologia de sementes. Introdução a patologia de sementes e testes convencionais de sanidade de sementes para a detecção de fungos fitopatogênicos. Informativo ABRATES. v.20, n.3. p.1013, 2010.

BRITO, N.M. et al. Efeitos de óleos essenciais na germinação de sementes de Cereus jamacaru. Revista Brasileira de Ciências Agrárias, v.5, n.2, p.207-211, 2010.

BRASIL. Ministério da Agricultura. Secretaria Nacional de Defesa Agropecuária. Regras para análise de sementes. Brasília: Ministério da Agricultura, Pecuária e Abastecimento, 2009. 395p.

COMBRINCK, S. et al. In vitro activity of eighteen essential oils and some major components against common postharvest fungal pathogens of fruit. Industrial Cropsand Products, v.33, p.344-9, 2011.

IBGE. Instituto Brasileiro de Geografia e Estatística. Levantamento sistemático da produção agrícola. Disponível em: http://www.sidra.ibge.gov.br.Acesso em: 10 jan. 2015.

IBRAHIM, L.et al. Composição química e atividade

Rev. Bras. PI. Med., Campinas, v.18, n.1, supl. I, p.279-287, 2016. 
antimicrobiana do óleo essencial e seus componentes do libanês Syriacum origanum L. Journal of Essential Oil Research, v.24, n.4, p.339-345, 2012.

LARRÉ, C.F. et al.Influência do 2,4 epibrassinolídeo na tolerância ao estresse salino em plântulas de arroz. Semina, v.35, n.1, p.67-76, 2014.

MAGUIRE, J.D. Speed of germination-aid in selection evaluation for seedling emergence and vigour. Crop Science, v.2, n.2, p.176-199, 1962.

MAZZAFERA, P. Efeito alelopático do extrato alcoólico do cravo-da-índia e eugenol. Revista Brasileira de Botânica, v.26, n.2, p.231-238, 2003.

MENDONÇA, M.B. et al. Isolamento e identificação de fungos com potencial patogênico para a saúde humana em material vegetal de uso medicinal comercializado em Manaus. Horticultura Brasileira, v.27, p.1208-1214, 2009.

MENEZES, M.; ASSIS, S.M.P. Guia prático para fungos fitopatôgenicos. 2.ed. Recife: UFRPE, Imprensa Universitária, 2004. 106p.

MONDEGO, J.M. et al.Controle alternativo da microflora de sementes de Pseudobombax marginatum com óleo essenciail de copaíba (Copaifera sp.). Bioscience Journal, v.30, n.2, p.349-355 2014.

MORAIS, L.A.S. Influência dos fatores abióticos na composição química dos óleos essenciais. Anais... (Suplemento - CD Rom), v.27, n.2, p.4050-4063, 2009.

MOREAU, J.S. Germinação de sementes em diferentes substratos e caracterização morfológica de plântulas de Anadenanthera macrocarpa (Benth.) Brenan. 2011. 45p. Monografia (Graduação em Agronomia), Universidade Federal do Espírito Santo, Alegre.

MUNIZZI, A. et al. Qualidade de sementes de quatro cultivares de soja, colhidas em dois locais no estado de Mato Grosso do Sul. Revista Brasileira de Sementes, v.32, n.1, p.176-185, 2010.

OLIVEIRA, J.A. et al. Secagem e armazenamento de sementes de sorgo com alto e baixo teor de tanino. Revista Brasileira de Sementes, v.33, n.4 p.699-710, 2011.

PENHA, J.S. Determinação da taxa de fecundação cruzada natural e diversidade genética em feijão-fava por marcadores microssatélites. 2014. 36p. Dissertação (Mestrado - Genética e Melhoramento). Universidade Federal do Piauí, Teresina.

PIVETA, G. et al. Superação de dormência na qualidade de sementes e mudas: influência na produção de Senna multijuga (L. C. Rich.) Irwin \& Barneby. ActaAmazônica, v.40, n.2, p.281-288, 2010.

SANTOS, A.C.A. et al. Efeito fungicida dos óleos essenciais de Schinusmolle L. e Schinus terebinthifolius Raddi, Anacardiaceae, do Rio Grande do Sul. Revista Brasileira de Farmagnosia. v.20, n.2, p.154-159, 2010.

SILVA, F.A.S. Assistat-Programa de análises estatísticas, Versão 7.7 beta. Campina Grande: UAEG-CTRNUFCG, 2012. Disponível em: http://www.assistat.com/ index.html. Acesso em: 02 Mar. 2014.

SILVA,P.V.; PASIN, L.A.A.P.Efeito de extrato aquoso de Cymbopogon citratus Staupf (capim-limão), Ocimum basilicum L. (manjericão), Vernonia scorpioides (piracá) na incidência nas sementes de Helianthus annuus L(girassol). In: X ENCONTRO LATINO AMERICANO DE INICIAÇÃO CIENTÍFICA E VI ENCONTRO LATINO AMERICANO DE PÓS-GRADUAÇÃO, 2911.,2006, São José dos Campos. Anais...São José dos Campos: Revista Univap, 2006. 157p.

SODAEIZADEH, H. et al. Herbicidal activity of a medicinal plant, Peganum harmala L., and decomposition dynamics of its phytotoxins in the soil. Industrial Cropsand Products, v.31, n.2, p.385-394, 2010.

SOUZA FILHO, A.P.S. et al. Efeitos potencialmente alelopáticos dos óleos essenciais de Piper hispidinervium C. DC. e Pogostemon heyneanus Benth sobre plantas daninhas. Acta Amazonica, v.39, n.2, p.389-395, 2009.

VIEGAS, E.C.et al. Qualidade fisiológica de sementes armazenadas de amendoim influenciada pelos produtos sintéticos e de origem vegetal. Revista Brasileira de plantas Medicinais, v.7, n.3, p.79-85, 2005.

ZIMMERMAM-FRANCO, D.C.et al. Antifungal Activity of Copaifera langsdorffii Desf Oleoresin against Dermatophytes. Molecules, v.18, n.10, p.12561-12570, 2013.

Rev. Bras. PI. Med., Campinas, v.18, n.1, supl. I, p.279-287, 2016. 